\title{
Change Matters; Theories of postdigital textiles and material design
}

\author{
IGOE Elaine \\ University of Portsmouth, UK \\ * elaine.igoe@port.ac.uk \\ doi: 10.21606/dma.2017.621
}

\begin{abstract}
This paper identifies examples of postdigital practice in textile and material design and uses the theories of New Materialism and the concept of the New Aesthetic to understand contemporary practice methods and outcomes. In the context of Zygmunt Bauman's Liquid Modernity it seeks to develop a theoretical context for designing textiles and materials that may be crafted algorithmically, that are alive with agency and pervasive in our subjectivity. Using key examples of contemporary designers, this paper identifies the deepening relationship between textiles and material design practice in the postdigital era. It begins to trace a legacy that asserts a continuity from textiles and material design practice in more traditional conventional formats to future and emerging design that engages and elicits both the physical and digital aspects of our culture in fluid times.
\end{abstract}

Keywords; postdigital, textile design, design theory, materials

\section{Introduction}

Its never not going to be like this.

Everything feels new and exciting for once.

I think in texture, shape, colour, big swathes of fabric flowing and almost having a liquidus texture to them. Molecules that are burstable, kind of mutate and turn into their own chemical reaction... and then I go on the computer and I make them.

The words above, from designer Lucy Hardcastle (Mandelup 2016) describe a new type of practice in the field of textile and material design. The clamour of industry approval for Hardcastle's stunning sensual storytelling, meant that she began working with international brands whilst still studying her Masters in Information Design. Originally trained in textile design, Hardcastle's practice typifies the post-digital approach to design. She is a maker. Making in materials and making in code. 
Hardcastle uses glass blowing techniques, 3D printing, flocking, hand dyed fabrics, 3D rendering, digital animation, photography and sound effortlessly to create "real and imagined touch, visual illusions and sensual aesthetics" (Hardcastle 2017).

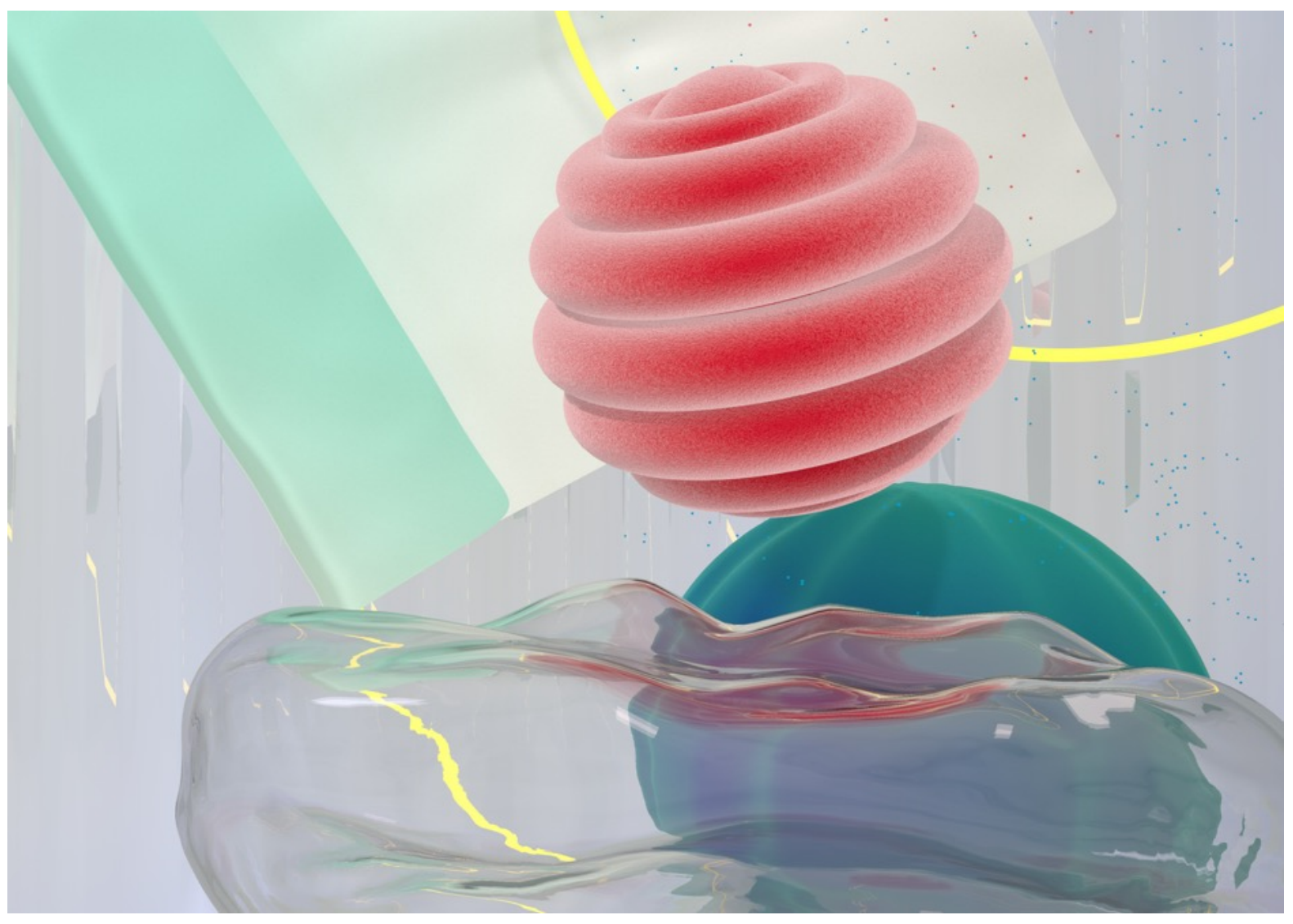

Figure 1 Conflate: A Celebration of Craft and Process for Blacks Visuals (2017) by Lucy Hardcastle Studio. Source: Lucy Hardcastle

Zeitguised are another design studio specialising in the creation of 'exquisite realities'. Zeitguised describe their work in the film GEIST.XYZ from 2016 as having a 'synthetic, ecstatic aesthetic' created through "handcrafted algorithmic textiles and procedural surfaces" (Zeitgeised 2001 - 2017). The work of Hardcastle and Zeitguised exists in two collaborating modes of understanding; the physical and the digital. In their work the two are inextricably blended in the product of what some are calling 'phygital' design.

Nimkulrat, Kane and Walton (2016) present a publication that begins to explore what it means to be 'Crafting Textiles in the Digital Age'. They note that textile practice is currently in a transitional phase, not only in regards to the aesthetics of crafting with or in the digital but also with due concern for the economic, social and environmental implications of that practice (Nimkulrat et al 2016, pg3). We know that design sits in a nexus (Kimbell 2012), and does not only have implications for but exists in a complex and tense relationship with the social, economic, environmental and the personal. The changes we see in design, in designing textile and materials, is itself a manifestation of changes in social, economic and environmental changes.

At The Design Research Society's Experiential Knowledge Special Interest Group conference in June 2017 entitled 'ALIVE. ACTIVE. ADAPTABLE' the premise was to discuss the collaboration between the physical and the digital in the design of materials. The organisers recognise that as materials acquire more possibilities for interaction, algorithmically, biologically or chemically, and gain increased digital or organic connectivity that we must begin to understand a design practice that deals with these agential materials (Karana et al 2017). 


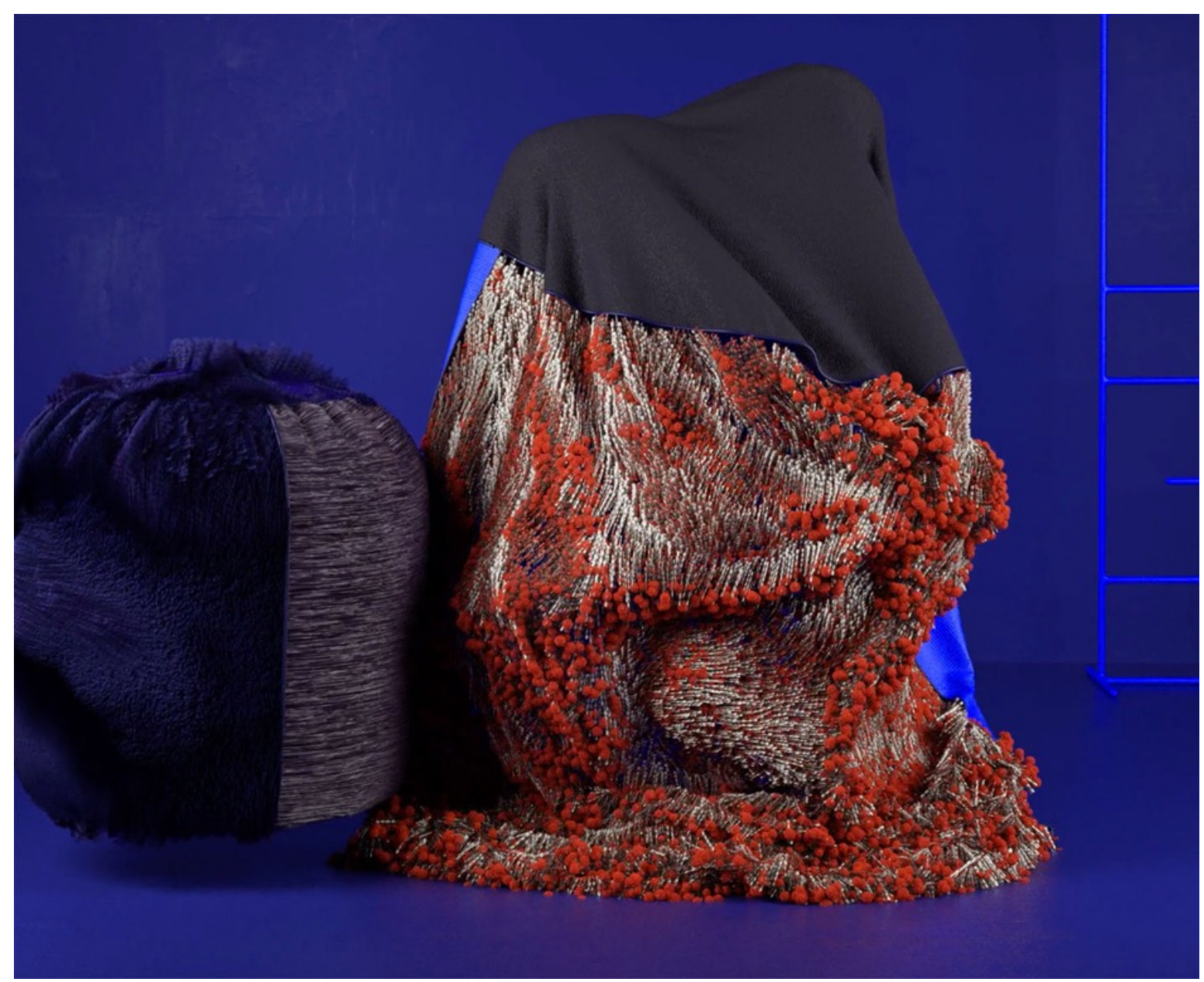

Figure 2 Still from Geist.XYZ: An exploration of handcrafted algorithmic textiles and surfaces (2016). Film available at http://www.zeitguised.com/things/geist-xyz Source: Zeitguised

This paper seeks to begin to develop a theoretical context for designing textiles and materials that may be crafted algorithmically and alive with agency. I ask how, in an age when 'its never going to not be like this', can we understand the deepening relationship between of textiles and material design practice? How might we trace a legacy that asserts a continuity from textiles and material design practice in more traditional conventional formats to future and emerging design that engages and elicits both the physical and digital aspects of our culture?

\section{Postdigital materiality}

At its broadest, (nonetheless), new materialism can be said to concern a series of questions and potentialities that revolve round the idea of active, agential and morphogenetic; self-differing and affective-affected matter. (Parikka \& Tiainen 2010)

Explorations into material agency (Karana et al 2017) and the expansion into interactivity and that of 'the smart' within the field of textiles align with the non-human turn of the concept of New Materialism. Its basis is in the rejection of the dualism of people and things and acknowledges an ontological hybridity in our reality (Gries 2015). In Postdigital Artisans (2015, p5) Jonathan Openshaw describes how we are "...reformulated by the digital moment, and where a digital mindset is inextricably entangled with our existence..." The concept of New Materialism (Parikka \& Tiainen 2010, Cole \& Frost 2010, Gries 2015) draws on a broad range of schools of cultural theory, and has in some ways given birth the concept of the postdigital. Openshaw believes that we now often experience a frustration with conventional material forms. We know that the material world is alive with possibility, the digital world has taught us to expect this, yet outside of the screen we can 
feel let down by materiality. The artisanal work that Openshaw showcases in his publication collaborates the digital and physical; this is the essence of postdigitality. Our past heroism of the digital, and indeed the handcrafted, are cast aside to explore and debate new working methods and outcomes of design.

The space between the haptic and the computational; the glitchy, awkward space between analogue and digital formats is the realm of the 'New Aesthetic'. This is a term that goes hand in hand with the postdigital and has been attributed to James Bridle, who in 2011 began collating imagery on his blog new-aesthetic.tumblr.com

\begin{abstract}
Whether a frame from an online video, or a screen capture of an online map (remember, digital maps are animations on pause), or fragments of code or spam; all of these are snippets, they are only momentary representations of ongoing processes - as indeed the New Aesthetic is intended to be. Each image is a link, hardcoded or imaginative, to other aspects of a far greater system, just as every web page and every essay, and every line of text written or quoted therein, is a link to other words, thoughts and ideas. Again, in this the New Aesthetic reproduces the structure and disposition of the network itself, as a form of critique. (Bridle 2013)
\end{abstract}

The 'New Aesthetic' was coined with little thought or understanding of the theory of aesthetics or to the significance the term would go on to garner. Bridle's explanation simply describes an experience, visual but perhaps moving or virtual, of that which is digitally networked. The New Aesthetic, although developed to describe a type of visual imagery, has some use for us in describing new forms of materiality and textility that are networked or seek to represent and critique it as it happens. In recent decades, the proliferation of smart textiles and materials bound up in our networked world show us that an internet of soft things is already in existence ('The Internet of Soft Things' is a project by Kettley et al 2016).

\title{
3. The tension of oscillation; the uncertainty of liquefaction
}

Recognising the ever-fluctuating position of design in and between the nexus of the social, economic, environmental and the culturally subjective/objective is a trait of postdigital designers. The notion of a version of modernity that is in flux was developed by sociologist Zygmunt Bauman in his theory of 'Liquid Modernity' (2000). He questions the postmodern era, criticises the speed at which it was named and posits that society moved from a 'solid' modernity to a 'liquid' modernity rather than into a postmodern state. He argues that contemporary ideas and ideologies are unlikely to be given enough time to solidify, and cannot serve as frames of reference for human actions. (Bauman 2007, pg 1)

In the use of metaphoric material terms to describe ways of being, Bauman's texts can be given a certain reading by those working in the field of textiles and materials. In the foreword to 'Liquid Modernity', entitled 'On Being Light and Liquid' Bauman explains the development of his theories from the phrase famously used in The Communist Manifesto 'melting the solids'. The solidity of the pre-modern state was to be dissolved and reconstituted to make way for a new and improved solid, one that would last, be reliable, predictable and manageable (Bauman 2000, pg 3) in a truly Modern age.

Bauman outlines how we have come to a second modernity, a modernity that has turned back on itself, not another melting or reconstitution but a liquefaction of our previous state, principally moving from 'system' to 'society' and from 'politics' to 'life-policies' resulting in an individualised, privatised version of modernity. He highlights patterns of dependency and interaction as a key area for liquefaction in this epoch. Old concepts still exist in a type of zombie-like limbo, neither dead or alive, but in our fluid state, it remains to be decided whether these concepts continue to exist, reincarnated or whether they must be laid to rest. 
Bauman reminds us of the relationship between time and state of matter. Solids, with clear dimensions, holding their shape and resist time, while for liquids, it is time that counts. Fluids do not keep any shape for long, they are prone to change; in shape and flow, holding a shape but for a moment. Fluids are mobile, able to splash or ooze, drip or spray. When solids and liquids meet, liquids move around them or infiltrate them, while solids become drenched or moistened, requiring a lengthy process of renaturing. "Descriptions of fluids are all snapshots, and they need a date at the bottom of the picture." (Bauman 2000, pg 2) This line from Bauman feeds the justification of the post-digital and the New Aesthetic.

The cultural theory of the meta-modern is an explanation of contemporary society and culture as reflexive, uncertain and oscillating. Vermeulen \& van den Akker developed the theory in 2010 as notions of the postdigital era also began to be concretised. Vermeulen (2012) has described the metamodern as an 'open source document' not a philosophy but an attempt at a vernacular. Indeed, metamodernism has developed through an online prescence with multiple contributors posting examples and critiques of art, fashion, literature and music that represent that vernacular relevant to contemporary culture which postmodernism is inadequate for. Metamodernism describes a culture between and beyond, a position which is in a constant, yet unbalanced state of change. It is clear that postdigital design practice aligns with the fundamental concepts of metamodernism.

I have posited the notion of 'textasis' (Igoe 2013) as a text-ile in tension, recognizing the etymological and metaphorical connection between text and textile, thinking, speaking, writing and making. It represents the definition of textile thinking in its interconnection of the material and immaterial in tasis. Textasis suggests a movement between stasis/enstasis, that which is unmoving, immobilised, subordinated, standing firmly within oneself, to ex stasis/ekstasis, flow, excess, ecstasy, joy, insubordination, to be outside of oneself, the transgression of boundaries. In textasis, textiles (as a disciplinary area) is in a tension between its material form and how it performs and what it represents beyond the tactile. How is textasis manifested through the New Aesthetic and New Materialism of the postdigital?

The postdigital defines a time in which the novelty of the digital has been overcome and its value is becoming fully integrated, embedded, into our lives. But what actually defines the digital? Etymologically, the digital merely denotes something divided into discrete units; digits; fingers. A digital system can be basic or highly complex, but it is systematic and traceable. The shared reference points and language of the digital and the textile have been stated clearly before (Plant 1997) but it is worth reiterating and unpicking this in the postdigital era.

Cramer (Berry \& Dieter 2015, pgs 17-18) reminds us that the digital need not be electronic and the analogue can indeed perform computationally. He gives the example of the meme of 'the hipster and the mechanical typewriter' as an artefact-in-use which could be considered postdigital; a digital system in its predetermined set of letters, punctuation marks and numbers, yet simultaneously and colloquially, analogue, performing as if flaunting its 'wireless' technology. The information the typewriter creates varies on a continuum; the quality of mark made dependent on how much use the ink tape has had or how many times the keys have been struck. Cramer's example hints at the notion that the perception of an artefact as digital or analogue can be dependent on how we interact with it. Unused on a desk, the typewriter remains elementally digital in an analogue context. Well used, on a park bench in 2013, it performs a commentary on the digital while romanticising the analogue.

Textiles, in their typical form, can be understood as digital at the time of their production; numbers of counted warp strands, a predetermined number of stitches. What makes them analogue is our relationship with them, the way we interact with them, wear them out, imbue ourselves into them. Yet, once out of use they can be unravelled, each strand or row once again can be counted. Cramer $(2014, \mathrm{p} 18)$ points out that "The structure of an analogue signal is determined entirely by its correspondence (analogy) with the original physical phenomenon which it mimics." As is understood, 
textiles and cloth were often historically created to mimic natural surfaces such as hair, fur and skin, not only for their function but for their sensorial qualities. And so, (elementally) digital textiles ape the analogue qualities of the body. This analogy then evolves ambiently to becomes a sort of metaanalogue surface. Textile designers of the New Aesthetic are taking these postdigital, meta-analogue surfaces into a new realm of (post)digitality. Their work, situated in and embracing a glitchy, oscillating era exposes and manifests this process of becoming in the context of fluid modernity.

Lucy Hardcastle and Zeitguised's work extends this oscillating process dimensionally. Real surfaces, materials and fabrics are created, photographed, enhanced, digitally rendered and animated. Hardcastle works in the analogue as she dyes and drapes them, makes them digital by modelling them, we make them analogue by our experience of them (albeit currently a dissonant one via screen). At that point, her experiential knowledge as a designer and ours align on a varying continuum in our longing for the seeming simplicity (yet indescribable sensorialism) of the analogue in the disorientating complexity (yet algorithmically traceable nature) of the digital. In their uncanny nature, the hyper-realness of her work reveals the unfamiliar hidden within the known.

In 2016, textile designer Nadine Goepfert collaborated with Zeitguised in the development of 'Distort \& Transform'; a project aiming to integrate digital research and the exploration of experimental textiles in 'real' haptic objects. The outcome was a rug which explored imagery from the Zeitguised film from 2016 'GEIST.XYZ'. The outcome of this collaboration is an abstract rug, hand knotted, sculptural in shape with varying texture, sumptuously colourful, textured and well crafted. It sits, inviting an experience but struggles for attention in comparison to the hyper-real, multimodal lusciousness of the digital work itself. The tangible, haptic object is arguably less enticing, less stimulating and too real.

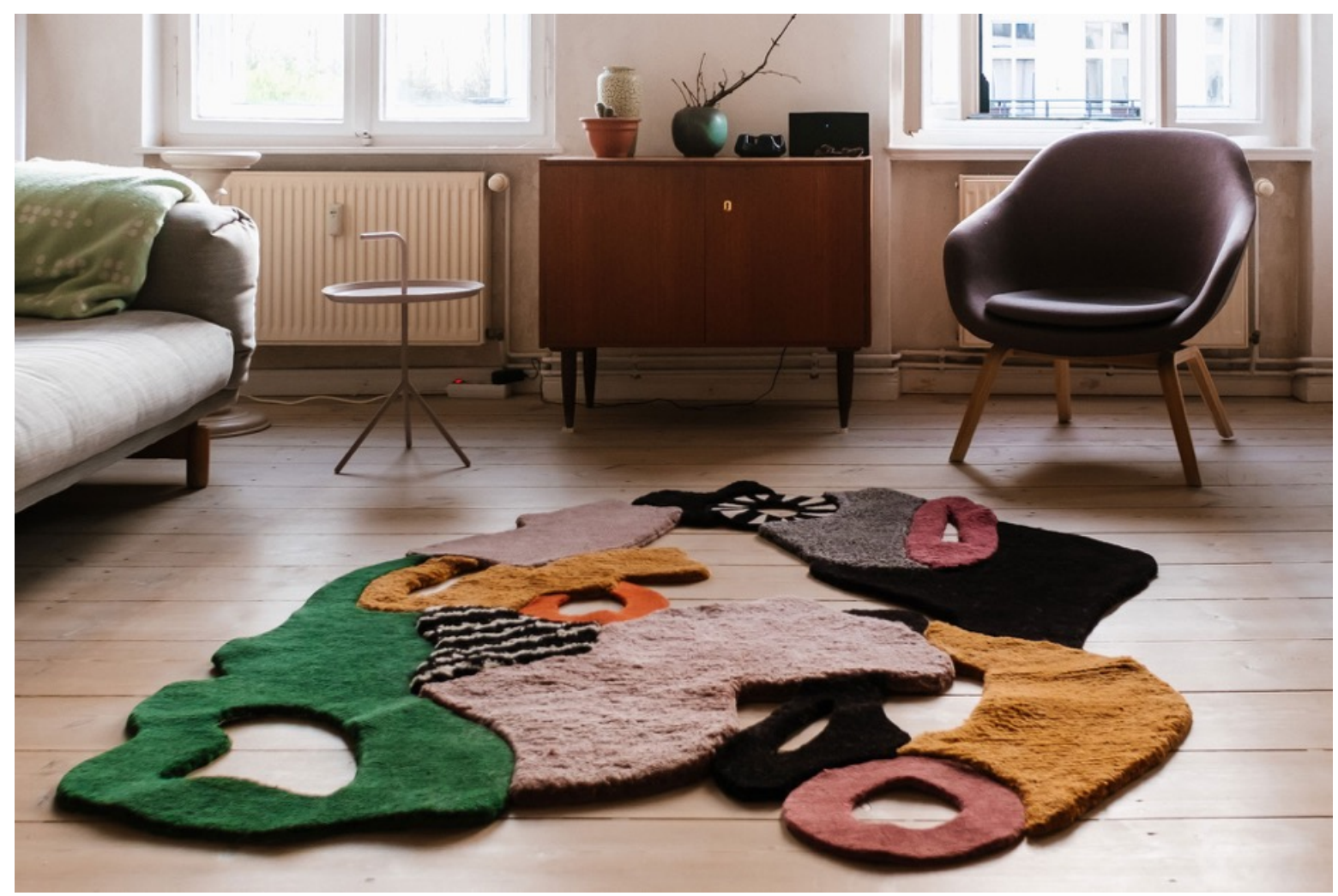

Figure 3 Geist.XYZ rug by Nadine Goepfert (2016) Source: Zeitguised

The ways in which the New Aesthetic mediates rely on a complex framework of human and non-human 'actants' that are socially networked, act upon natural resources and the social fabric, and create new variations of semiotic construction (in the sense of agency that produces meaning.) (Paul and Levy 2014, p41) 
Paul and Levy refer to the New Aesthetic's socio-ontological foundations in Latour's Actor Network Theory (2005) which rejects the hierarchy of human existence over that of objects and delegates agency to the non-human, linking the natural, social and semiotic. Textiles and materials operating in the postdigital area have the prescence/agency imbued by the cultural history of the surface as a (designed) object with the significance of the networked representation. The interface of the screen, currently provides a dissonance between the activity and depth of our online experience and the physical sedentary of sitting at a computer. Screens will become materials in a co-poeisis of design, set in tense relationship, questioning where or if there are any boundaries, becoming more ambient as well as more unreal, awe-inspiring and dis-orientating. This questioning of the boundaries between nature and culture, between subject and object underpins theories of 'New Materialism' (Gries 2015).

\section{Changing state}

Notions of transitions and transgressions between textiles and material design and the jolting oscillation or powerful flow of the liquid state of our era fosters instability. Postdigital practitioners explore and critique this instability. However, just as things move together, they can also move apart. Openshaw (2015 pg 9) comments that society does not want the gap between the digital and the physical to be closed completely; just as our hunger for the digital experience has grown we have also seen a desire to rediscover some of the most tactile and analogue forms of human culture. Benjamin's concept of the lost aura in the age of mechanical reproduction can be applied to defend this dissonance.

Bridle (2013) recognises the power of the aura of the object and insinuates that the New Aesthetic is concerned with representing the nature of the aura through agency, stating that,

...the New Aesthetic is concerned with everything that is not visible in these images and quotes, but that is inseparable from them, and without which they would not exist.

This statement flows the digital and analogue back towards each other one again. The politics of the networked aesthetic of the New Aesthetic relates to real, human experience. Auras include traces, that of the way something is made and used. Robbins, Giaccardi \& Karana (2016) discuss the socioecological context of material traces; the convergence and reciprocity of people, practices and materials and advise that designers must engage with the critical value of traces as we design in more layers of digital capabilities.

Nonetheless we experience a significant proportion of postdigital culture via screens. These interfaces are reformulating our view and experience of our worlds and our ability act on it and within it (Openshaw 2015 Pg 9). Our screens are now mostly hard, flat glass. Our tactile relationship with them is limited but yet the glass absorbs and transforms us; like it absorbs heats and refracts light. This screen has power at and on its (currently) unmalleable surface.

The postdigital, as an aesthetic, gestures towards a relation produced by digital surfaces in a bewildering number of different places and contexts. This interface-centricity is not necessarily screenic, however and represents the current emerging asterism that is formed around notions of art, computation and design. In this conception, the postdigital is not purely a digital formation or artefact - it can also be the concepts, networks and frameworks of digitality that are represented... (Berry 2014 pg 44) 


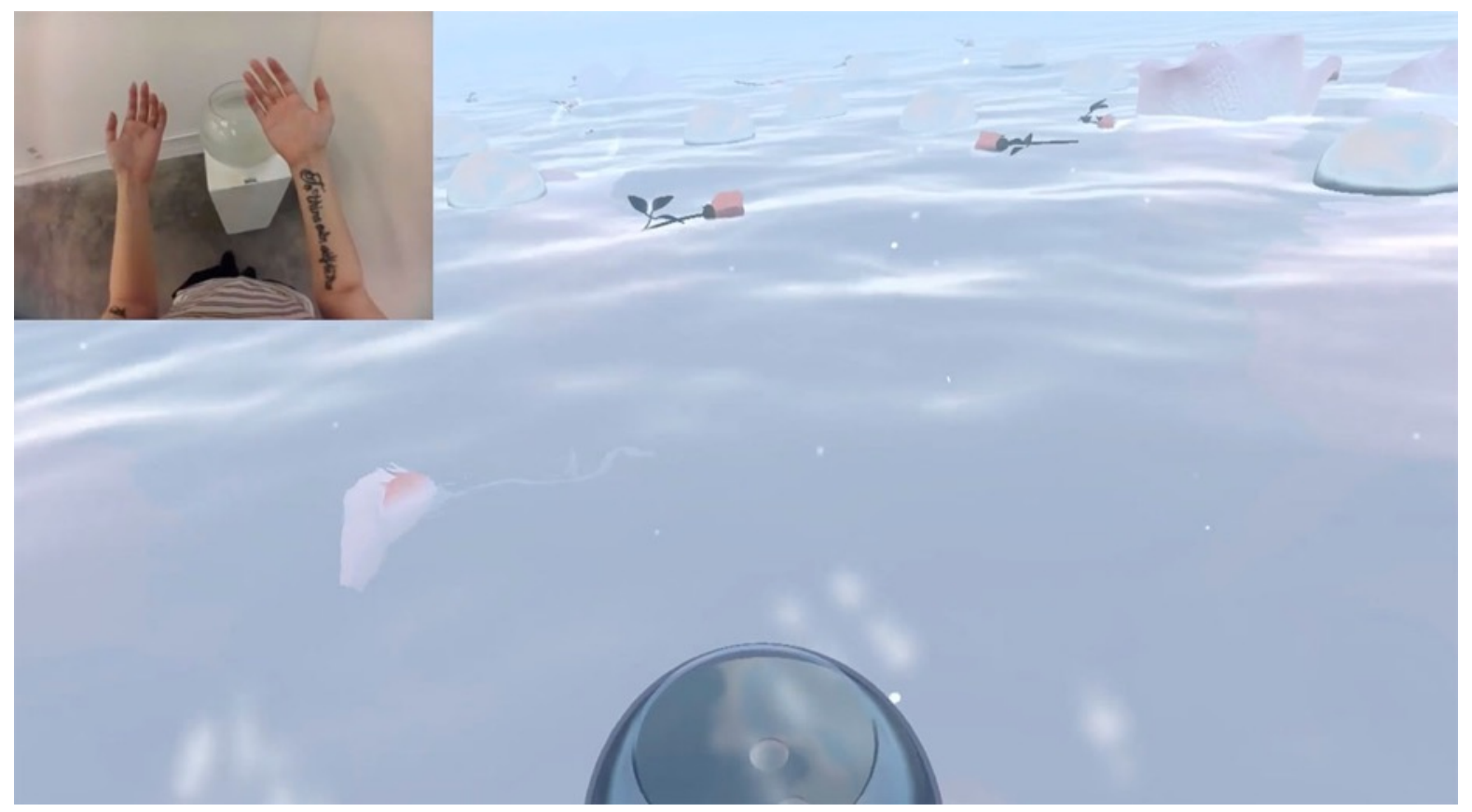

Figure 4 Composite image from Assimilation (2016) by Molly Smisko. 'Assimilation' is a mixed reality design work. The image in the top left shows the arms and hands of a user who is wearing a virtual reality headset in the physical environment. The main image shows what that user is correspondingly experiencing in the digital, virtual environment. Video available at https://vimeo.com/176478169 Source: Molly Smisko

Postdigital design in textiles and materials is often centrally concerned with this very relationship and expresses a form of the 'New Aesthetic'. From the hyper-sensuality of Hardcastle's untouchable imagery to Amy Winters' work in the field of $\mathrm{HCl}$ where she develops responsive surfaces, organic user interfaces and transitive materials to soften our relationship with the computational (Winters 2016); and further still to the work of Molly Smisko a textile designer working in mixed realities. In works like 'Assimilation' (2016) Smisko immerses us in the interface using a combination of 'passive, haptic' materials and virtual worlds to deepen sensory experiences and at other times create a glitch-like disconnect that prompts us to question what we are experiencing.

All of these works force us to question where the interface begins and ends; On the screen? On our eyes? On our fingertips or skin? Inside our heads? Through the postdigital's 'interfacecentricity' we must confront the notion of the subjective-objective boundary. I use Ettinger's matrixial theory to support the inherent relationality of textiles thinking and the complex relationship we have with textilic materials, both when designing and interacting with them (Igoe 2013). Ettinger's theories were developed in the context of feminist film theory but establish the gaze as a trans-subjective encounter which extends into other sensory realms. Ettinger emphasises the co-poiesis at play within the encounter which serves as transgressional and yet productive as it forges new linking;

... a process of interpsychic communication and transformation that transgresses the borders of the individual subject and takes place between several entities. Ettinger (2006 pgs 181-182)

Through this process the limits, borderlines, and thresholds conceived are continually transgressed or dissolved, thus allowing the creation of new ones. Ettinger (1992) cited in Pollock (2009 pg 3)

Ettinger's extension of the Lacanian gaze into a matrixial, (networked) subjective encounter encompasses the politics of the New Aesthetic of the postdigital age as well as New Materialsm's questions surrounding morphogenesis in the context of our Liquid Modernity. 


\section{Thin Machinery}

Berry's text, The Postdigital Constellation, (Berry \& Dieter 2014, pgs 44-45) provides an exploration of the surface as performative, calling them "thin machinery, containing not just the possibility of a hermeneutic encounter but also an agency drawn from computation itself." In the postdigital, the New Aesthetic work exposes and at times roughs up the grain of computation into an analogue form. Postdigital textiles and materials can provide this in reverse, providing a hermeneutic experience through its analogous agency with the potential for a digital encounter which may enhance and/or make uncanny the experience altogether.

So what of textiles and materials in this epoch of 'The New' - materialism and aesthetic? Hardcastle in calling one of her projects 'Intangible Matter' and Zeitguised with their use of the 'phygital' are both trying to capture something which transgresses current boundaries of thought. Work which exists in two modes of understanding, but yet is also a snapshot, its meaning is transient. They are trying to express the nature of something which has two states at the same time. By its nature, this practice is diverse and difficult to label (for very long).

Other emerging designers working at the interstice of design, craft, science and computing include Lauren Bowker, founder of The Unseen. She is a textile design scientist developing colour changing dyes. Bowker is a self-styled witch, channelling 'magick' in order to visualise the data that surrounds us and that we create with our own bodies. Bowker hides the science behind the spectacle. She labels her work not as design, nor chemistry but alchemy. Anna Neklesa, having practised interior design and textiles creates 'molecular tailoring' and she too calls herself a 'haute couture alchemist'. Neklesa works with scientists to develop her 'living cotton' materials which rely on time as an essential dimension to the outcome. Neklesa's work represents textiles in textasis in our liquid times. Aligning with Vallgårda's notion of 'computational composites' (Karana et al 2017 pg 8) the familiarity of cotton cloth is made uncanny and given a different, unnerving performativity through its voluntary movements. It is indeed alive.

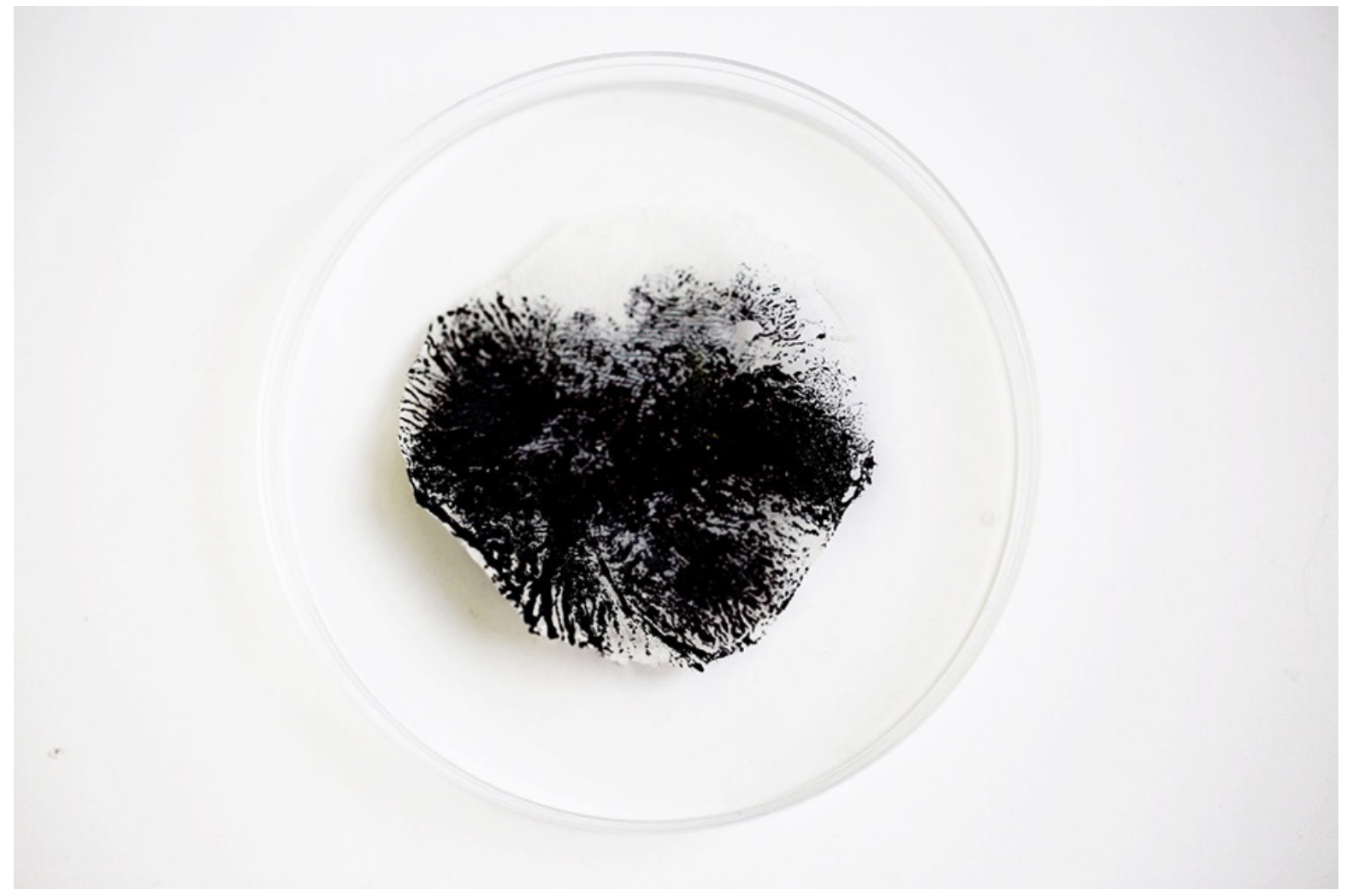


Caroline Bassett (Berry \& Dieter 2015 pg 146) sets out a critique of the postdigital in feminist terms and calls for a technophile feminism, but one that does not operate in quasi-mystical terms, such as does Bowker and Neklesa with their alchemist monikers that hold on to zombified ideas of how their practice can be understood. Bassett calls for a feminist approach that,

... deals in new materialities and that seeks genuinely new subjectivities... and ...new intersections between different forms of thinking about the relationship between weird matter and the fantastic forms of objects and bodies under capitalism.

Pioneering postdigital practice for almost two decades, Carole Collet has been a key figure in exemplifying practice which performs in the way Bassett describes above. Her 2012 BioLace speculative design project exists between synthetic biology and textile design but does not adopt a 'Mother Nature' persona. Photographs of hydroponically grown black strawberry plants whose roots have grown into a formal and recognisable lacy structure prompt us to question what we are looking at and how do we understand it and how can we take it and use it?

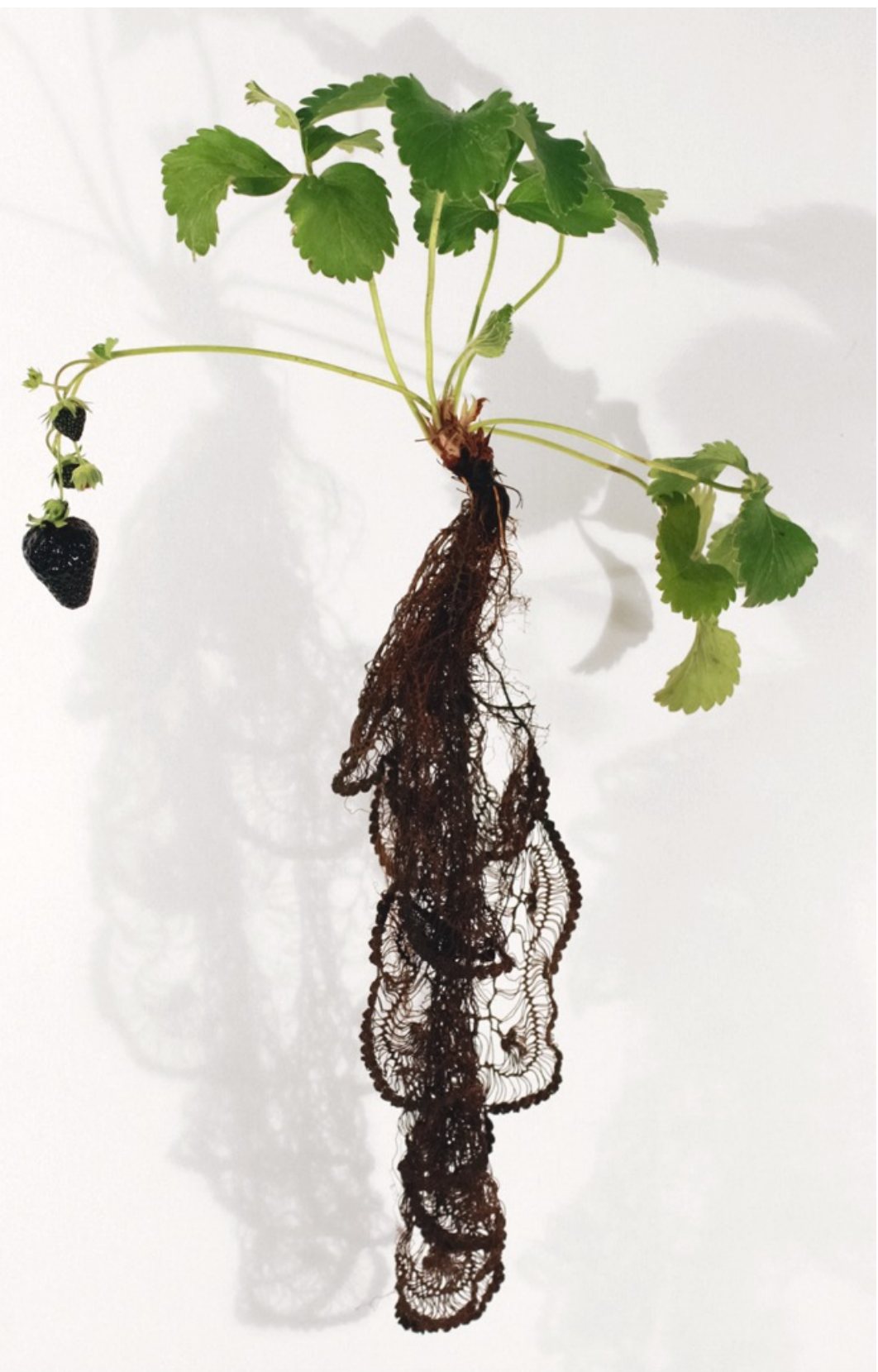


Miriam Azaria works through design activism to synthesise material science and textile design to develop new models of design for circularity. Her 2014 DeNAture project envisages fibres encoded 'like tree rings' for the purposes of future cyclability. In the space she has manifested between fibre and computational code, she used a short film to communicate her ideas.

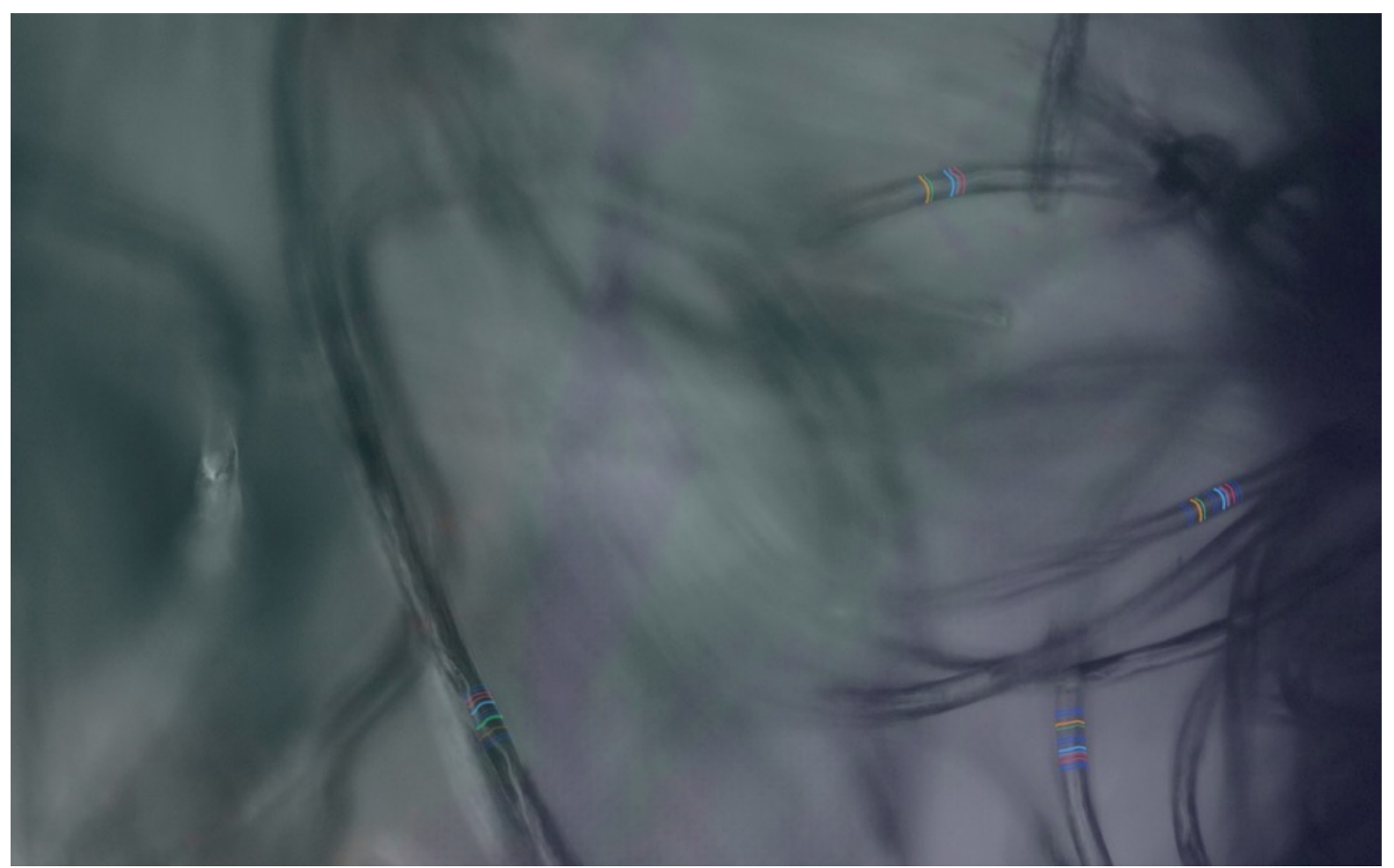

Figure 7 Still from DeNAture by Miriam Azaria (2014). A visualisation of encoded fibres. Source: Miriam Azaria

I have intentionally made no categorisation between the types of works of textile and material design that I discuss in this paper. They exist along a continuum of postdigital practice under labels which do not helpfully describe their purpose or action. They all sit at the interstice of digitality and materiality, exemplifying textasis in their oscillation between the objective, subjective and aesthetic. The corroboration of aspects of the New Aesthetic with the gravitas of the developing canon of New Materialism is interesting and useful when examining postdigital textile and material design. This work exists in a merging blur between the two. The New Aesthetic dealing with the politics of image and New Materialism with the politics and subjectivity of matter. The point of convergence is the space of debate and creative opportunity; a 'swell in the flow' of our liquid times. Nimkulrat et al (2016, pg 9) suggest that textiles cannot exist without material outcomes and can never exist solely in digital space. With this understanding that design and the act of designing is occurring in a social epoch of state change, we must accept that our current concept of what textile and material design are today is a zombified thought, we must decide whether it will flow in the liquidity or be flooded out. My aim here is to encourage a liquefaction of the notions of 'textile' and 'material' in this slippy-dippy state we find ourselves in.

The notion of the 'textile' is in particular danger of solidifying. The last two decades have seen an exponential diversification of practice in the field of textile design fed by new technologies, addressing changes in interactions between humans and with our environments. Practitioners educated in the field of textile design are working within material innovation design, and certainly are beginning to prefer to use the label of 'material designer' when describing their working practices. They, as designers, along with their work are in positive liminality. Which way to turn in this postdigital liquid modernity? 
Textiles? Too decorative, too quick, too familiar, too often ignored.

Materials? Too impersonal, too slow, too plain, too performance oriented.

Postdigital design practitioners in textiles and materials work in a way which critiques the status quo and exposes the anomalies, riding the waves of our liquidus state. It is the job of the theoreticians of postdigital textile and material design to interrogate and expose our networked state and keep an eye on the horizon for the next surge.

\section{References}

Azaria, M. (2014) DeNAture. Retrieved from https://www.miriamribul.com/

Bassett, C. (2015) Not Now? Feminism, Technology, Postdigital. In D. Berry \& M. Dieter (Eds) (2015) Postdigital aesthetics; Art, Computation and Design. (pp $136-150)$ Basingstoke: Palgrave Macmillan

Bauman, Z. (2000) Liquid Modernity. Cambridge: Polity

Bauman, Z. (2007) Liquid Times. Cambridge: Polity

Berry, D. (2015) The Postdigital Constellation. In D. Berry \& M. Dieter (Eds) (2015) Postdigital aesthetics; Art, Computation and Design. (pp $44-57$ ) Basingstoke: Palgrave Macmillan

Berry, D. \& Dieter, M. (eds) (2015) Postdigital aesthetics; Art, Computation and Design. Basingstoke, UK, Palgrave Macmillan

Bridle, J. (12 June 2013) The New Aesthetics and Its Politics. Retrieved from http://booktwo.org/notebook/new-aesthetic-politics/

Bridle, J. (2011 - present) Retrieved from http://new-aesthetic.tumblr.com/

Cramer, F. (2015) What is 'Post-digital'? In D. Berry \& M. Dieter (Eds) (2015) Postdigital aesthetics; Art, Computation and Design. (pp 12 - 26) Basingstoke: Palgrave Macmillan

Collet, C. (2017) BioLace Retrieved from http://www.designandlivingsystems.com/biolace/

Cole, D. \& Frost, S. (Eds) (2010) New Materialisms; Ontology, Agency, and Politics. Durham: Duke University Press

Ettinger, B. (2006) The Matrixial Borderspace. Minneapolis, MN: University of Minnesota Press

Goepfert, N. (2016) Distort \& Transform. Retrieved from http://nadinegoepfert.com/

Gries, L. (2015) Still Life with Rhetoric: A New Materialist Approach to Visual Rhetorics. Utah: Utah University Press

Hardcastle, L. (2017) Retrieved from https://www.lucyhardcastle.com/about/

Igoe, E. (2013) In Textasis: Matrixial Narratives of Textile Design (Doctoral thesis) Royal College of Art, London

Karana, E., Giaccardi, E., Nimkulrat, N., Niedderrer, K., Camere, S. (2017) Conference Proceedings of Alive. Active. Adaptive. International Conference on Experiential Knowledge and Emerging Materials. Delft: TU Delft

Kettley, S., Kettley, R., Brown, D., Briggs-Goode, A., Glazzard, M., Bates, M., Battersby, S. \& Lucas, R., (2016) Retrieved from https://aninternetofsoftthings.com

Kimbell, L. (2012) Rethinking Design Thinking: Part Two. Design and Culture: The Journal of the Design Studies Forum, 4(2), $129-148$

Latour, B. (2005). Reassembling the social: An introduction to actor-network-theory. Oxford: Oxford University Press.

Mandelup, L. (13 Dec 2016) The Fifth Sense, Episode 3: Making Codes with Lucy Hardcastle. Retrieved from https://youtu.be/y7hTuqxq14Y

Neklesa, A. (2017) Living Cotton. Retrieved from http://www.annaneklesa.com/

Nimkulrat, N., Kane, F. \& Walton, K. (2016) Crafting Textiles in the Digital Age. London: Bloomsbury.

Openshaw, J. (2015) Postdigital artisans; Craftsmanship with a New Aesthethic in Fashion, Art, Design and Architecture. Amsterdam: FRAME Publishers

Parikka, J. \& Tiainen, M. (2010) What is New Materialism? Retrieved from https://jussiparikka.net/2010/06/23/what-is-new-materialism-opening-words-from-the-event/

Plant, S. (1997) Zeroes + Ones: Digital Women \& the New Technoculture. In J.Hemmings (Ed) (2012) The Textile Reader. (pp $324-355$ ) London: Berg

Pollock, G. (2009) Mother trouble: the maternal-feminine in phallic and feminist theory in relation to Bracha Ettinger's elaboration of matrixial ethics/aesthetics. Studies in the Maternal 1 (1) [online]. London. 
Birkbeck College, University of London. Retrieved from

http://www.mamsie.bbk.ac.uk/back_issues/issue_one/GriseldaPollock.pdf

Potter, C. (23 Feb 2012) Tank Interviews Timotheus Vermeulen. Retrieved from

http://www.metamodernism.com/2012/02/23/tank-interviews-timotheus-vermeulen-about-

metamodernism/

Smisko, M. (2016) Assimilation. Retrieved from https://vimeo.com/176478169

The Unseen (2017) Retrieved from http://seetheunseen.co.uk/

Winters, A. (2016) Building a Soft Machine: New Modes of Expressive Surfaces. In A. Marcus (eds) Design, User Experience, and Usability: Technological Contexts. DUXU 2016. Lecture Notes in Computer Science, vol 9748. Springer; Cham

Zeitgeised (2001 - 2017) Retrieved from http://www.zeitguised.com/

About the Author:

Elaine Igoe is Senior Lecturer in Textiles and Fashion at the University of Portsmouth, UK and holds a PhD from the Royal College of Art, London. Elaine writes on textile and material design research and theory. 